\title{
Acute and chronic toxicity study of Valeriana wallichii rhizome hydro-ethanolic extract in Swiss albino mice
}

\author{
Lovelyn Joseph ${ }^{1}$, Rejeesh Edavan Puthallath², Sundarshanram Narayan Rao ${ }^{3}$ \\ ${ }^{1}$ Associate Professor, Department of Pharmacology, PK Das Institute of Medical Sciences, Vaniyamkulam, Palakkad, India, ${ }^{2}$ Assistant \\ Professor, Department of Pharmacology, Government Medical College, Palakkad, Kerala, India, ${ }^{3}$ Professor and Head, Department of \\ Pharmacology, Yenepoya Medical College, Mangalore, Karnataka, India
}

Aims and Objective: To evaluate acute and chronic (90 days) oral toxicity of Valeriana wallichii rhizome hydroethanolic extract in Swiss albino mice. Materials and Methods: Valeriana wallichii rhizome was subjected to extraction with Soxhlet apparatus, using ethanol (90\%) + water $(10 \%)$ mixture and dried withrotavapor. Phytochemical fingerprinting of the extract was done with LC/MS (Liquid chromatography-mass spectrometry). Limit Test for acute oral toxicity at $2000 \mathrm{mg} / \mathrm{kg}$ body weight was conducted according to OECD guideline no 425. Chronic 90 day oral toxicity study with three different dose groups (200, 600, $1800 \mathrm{mg} / \mathrm{kg} / \mathrm{body}$ weight/day) with selected in life parameters (physical, behavioural) and post mortem parameters (haematological, biochemical, gross necropsy and histopathological) as per WHO guidelines for testing safety of herbs was conducted. Results: Acute toxicity: no signs of abnormality, morbidity or mortality were observed during 14 days of observation. Chronic toxicity: Significant differences between the treated and control groups were observed in the following parameters: Loss of Auditory startle, Aggressiveness (Control > treated), Nasal discharge, Dyspnoea. At necropsy, tracheitis was observed in 3 cases. Results from Photoactometer test indicates dose dependent increase in sedative property. Conclusion: From this work it could be concluded that Valerianawallcihii rhizome hydroethanolic extract didn't exhibit mortality, morbidity or any other neurologic, hematologic or biochemical adverse effects apart from sedation which is extension of their known pharmacological activity, after single oral dose of $2000 \mathrm{mg} /$ $\mathrm{kg}$ bw (14 days of observation) or after once daily $200 \mathrm{mg} / \mathrm{kg}, 600 \mathrm{mg} / \mathrm{kg} 1800 \mathrm{mg} / \mathrm{kg}$ oral treatment for 90days in healthy adult Swiss albino mice.

Key words: Valerian, Valeriana wallichii, Toxicity, Preclinical toxicity, Swiss albino mice

\section{Access this article online}

Website:

http://nepjol.info/index.php/AJMS DOI: 10.3126/ajms.v7i2.13326 E-ISSN: 2091-0576 P-ISSN: $2467-9100$

\section{INTRODUCTION}

Herbal formulation named Valerian or Tagara is widely marketed worldwide mostly for sedative- hypnotic properties. The formulation include the underground organs of members of the genus Valeriana (Valerianaceae), as well as some related genera such as Nardostachys, are used in the traditional medicine of many cultures as mild sedatives and tranquillizers and to aid the induction of sleep. Valerianaofficinalis is the species most commonly used in northern Europe and retains its official pharmacopoeial status although it is most commonly encountered as an ingredient of herbal medicines. ${ }^{1}$ Indian valerian, Valeriana wallichii is commonly known as Tagara, is anherb recommended by Ayurveda and other ethno medicine streams of India for CNS activities like Sedative-hypnotic and anticonvulsant properties.

Research Guidelines for Evaluating the Safety and Efficacy of Herbal Medicines ${ }^{2}$ published by WHOstates that toxicological evaluation of medicinal plants has been neglected since prolonged and apparently uneventful use usually is considered as anevidence of its safety. However, a history of traditional usage is not always a 
reliable guarantee of safety since it was never evaluated scientifically to detect or monitor delayed effects, rare adverse effects, and adverse effects arising on chronic use of food supplements and nutraceuticals. Further many organizations like WHO and ICMR have expressed the urgent need for validation of indigenous medicines as these could be potential alternative to fill in the treatment gap due to lack of sufficient supply and further may help in the discovery of novel active principles and targets.

The widely used herb tagara consists of predominantly dried rhizome, stolon and small portion of root of Valeriana wallichii DC, (Fam. Caprifoliaeceae): a hairy perennial herb, growing in temperate Himalayas from Kashmir to Bhutan and Khasiahillsup to an altitude of $3,000 \mathrm{~m} .^{3}$ These plants have been the subject of considerable research, aiming at establishing the pharmacological basis of the activity with both animal and clinical studies. ${ }^{4}$ Valeriana wallichii is classified under family Caprifoliaeceae but until recent years Valeriana wallichii was classified under family Valerianaceae. In this work the older classification system is found to be more suitable since the phytopharmacological profile of the plant is better shared by the members of the family Valereaneceae than of Caprifoliaeceae.

Major pharmacological actions reported by the research publications involving experiments with Valeriana wallichii are sedative, hypnotic, ${ }^{5}$ anxiolytic, anticonvulsant, ${ }^{6,7}$ antidepressant ${ }^{8,9}$ anti-inflammatory ${ }^{10-13}$ analgesic anthelmintic ${ }^{11}$ antileismanial ${ }^{12}$ insecticidal hypotensinve antispasmodic ${ }^{13}$ antidiarrheal bronchodilatory ${ }^{14}$ antipyretic-analgeisic ${ }^{15}$ antioxidant hepatoprotective ${ }^{16}$ neuroprotective $e^{17}$ and possible molecular targets identified are $\mathrm{GABA}$, receptor, ${ }^{18}$ Glycine receptors, Adenosine, Nitric oxide signalling pathway, potassium channel opening, ${ }^{19}$ Anticholinesterase inhibition, modulation of brain monoamine levels inhibition of prostaglandin synthesis. ${ }^{20}$ Chemical constituents identified or isolated from the herb are 6-methylapigenin, acyl-linarin, ${ }^{21}$ minor iridoids, ${ }^{22} 4$-methoxy8-pentyl-1-naphthoic acid, ${ }^{23}$ methylelcosanoate, acevaltrate, is ovaleroxyhydroxydidrovaltrateanddidrovaltrate, ${ }^{24}$ podophyllotoxin and pinoresinol, 4'-demethylpodophyllotoxin, $\beta$-bisabolol, $\alpha$-kessyl alcohol, valeranone, bornylisovalerate and linarin-2-O-methylbutyrate. ${ }^{25}$ Clinical studies on stress management ${ }^{26}$ and sleep quality are published on this herb.

\section{MATERIALS AND METHODS}

\section{Collection, authentication and extraction}

Collection: The plant rhizome was collected from M. Subhash Chand and Sons, Karyanamerchants, Ghuhbazar, Paprola -Dist, Himachal Pradesh.176115. Authentication: The herb was authenticated and a voucher specimenwas deposited (no: R150) atto Agarkar Resarch Institute, Pune, India. Extraction: Herbs were cleaned removing foreign materials, ground to coarse powder, packed in a thimble made of muslin cloth, Water/Ethanol extract of Valeriana wallichii using exhaustive solvent evaporation technique with Soxhlet apparatus, using ethanol $(90 \%)$ + water $(10 \%)$ mixture as solvent was done, separated from solvent using rotavapor. Fingerprinting: HPLC-LCMS fingerprinting was carried out on a Shimadzu UFLC-XR (Ultra-Fast Liquid Chromatography) system which is interfaced to a Mass Spectrometry (Make: AB Sciex, Model: API 4000) instrument. ${ }^{27}$ Chromatogrphy conditions - Column: Stainless steel $250 \times 4.6 \mathrm{~mm}, 5 \mu \mathrm{m}$, Solvent: Methanol: $0.5 \%$ phosphoric acid (80:20). Flow rate: $1.5 \mathrm{~mL} /$ minute. LCMS Conditions - Ion Source: Electron Spray Ionization, Mode: Positive Ionization, Mass Scan Range: 100 - 1000 amu, Curtain Gas: 25, Gas 1: 35, Gas 2: 35, Temperature: 500, Ion Spray Voltage: 5500 (Figure 1).

\section{Study design}

Acute toxicity study: Acute toxicity was studied in a group of Swiss albino mice $(\mathrm{n}=6 ; 3$ males and 3 females) by administering $2000 \mathrm{mg} / \mathrm{kg}$ body weight of test drug Valeriana wallichii rhizome hydroethanolic extract(VWRHEE) orally as per OECD guidelines. The test method 425 was selected from many acute toxicity test methods available in view of the fact that this method provide an option for conducting a limit test at a single dose $(2000 \mathrm{mg} / \mathrm{kg}$ or $5000 \mathrm{mg} / \mathrm{kg})$ prior to the main test which helps to reduce the number of animals used if the test material is not mortal at the limit dose. Considering the published work on the test herb and long history of use without any report of toxicity the selection of this method is appropriate.

Chronic toxicity study: Ninety day repeated once daily oral treatment toxicity study with three $(200,600$, $1800 \mathrm{mg} / \mathrm{kg} /$ body weight/day) different dosegroups (Swiss albino mice, 2-3 months old, 25-30 $\mathrm{g} \mathrm{n}=6$; 3 males, 3 females), the first group was control [Vehicle - $0.2 \%$ Dimethyl sulfoxide], Second group was treated with $200 \mathrm{mg} / \mathrm{kg}$ body weight of test drug Valeriana wallichii rhizome hydroethanolic extract (VWRHEE) once daily orally, Third group was treated with $600 \mathrm{mg} / \mathrm{kg}$ body weight of VWRHEE once daily, Fourth group was treated with $1800 \mathrm{mg} / \mathrm{kg}$ body weight of VWRHEE once daily, with selected in life parameters (physical, behavioural) and post mortem parameters (haematological, biochemical, gross necropsy and histo-pathological) as per Research guidelines for evaluating the safety and efficacy of herbal medicines by World health organization. Parameters of the study are detailed below 


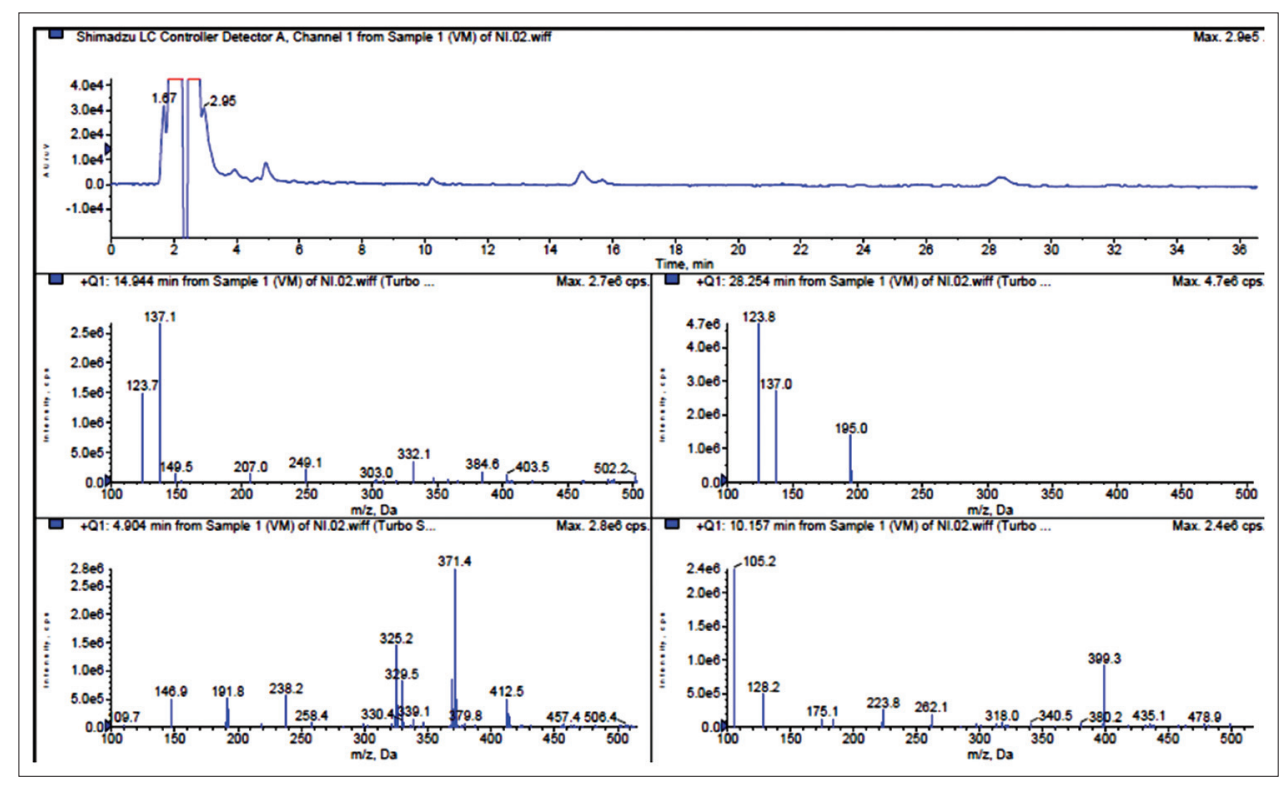

Figure 1: HPLC-LCMS fingerprinting of VwHEE

\section{Observations and examinations \\ General signs}

Changes in appearance \& general activity

Appearance: Eye, Nose, Ears, Mouth, Teeth, Fur, Nails, Tail, Genitals, Posture, Faecal consistency, Urine colour. General activity: Grooming, Photoactometer test, Rota rod test. In photoactometer test 'Percentage reduction in activity' was calculated using following formula.

$$
\frac{100 \times(\text { Predose activity }- \text { Postdose activity })}{\text { Predose activity }}
$$

\section{Neurological examination tests ${ }^{28}$}

Flexion Reflex: The mouse is picked up and the toes are pinched with forceps. The response is to move the foot away. Grasping Reflex: The mouse is picked up and the palm is touched with a wire. The response is to grip the wire. Righting Reflexes: When the mouse is put on its back, it turns over immediately; The animals is held in the lower back; when the body is tilted, its head moves opposite; The mouse is on its back when its head is tilted, its limbs move opposite; When the mouse is dropped, upside down, from $40 \mathrm{~cm}$, it lands right side up. Placing reactions: Hold the mouse near a table, when the dorsum of the paw contacts the edge of the table, the paw will be placed on the surface of the table. Equilibrium Tests: The mouse is placed on a bar and should be able to stay there for about 3 minutes. Corneal Reflex: Hold the mouse, touch the cornea (eye) with a hair - the mouse closes the eye. Pupillary Reflex: Look at the eye of a mouse with a red light, under a magnifying glass; turn on a white light - the pupil should constrict. Auditory Startle: When the mouse is quiet on a level surface, give a loud hand clap; it should flex forelimbs and extend hind limbs, arch the body. Toe
Spreading: Put the mouse on a piece of plexiglass over a mirror; when the plexiglass is tilted, the mouse spreads his toes. Head Shaking: When a puff of air is blown through a rubber tube to the ear, the mouse shakes his head. Conditions for scoring: The general procedure for each of the tests is to present the test stimulus and observe the reaction. The reaction to the stimulus should be immediate. If the animal produces the correct response, a 1 is scored. If no response or an inappropriate response is emitted, a 0 is used.

Body weight: Before the start of drug administration, once a week thereafter.

Haematological \& Blood chemistry examinations \& Hepatic function tests: Blood samples were taken immediately after Euthanasia, before autopsy. Total WBC, Total RBC, Lymphocytes (\%), Neutrophil (\%), Platelet count, Haemoglobin, Blood glucose, SGPT, SGOT (Mindray BC-2800Vet). Autopsy: After Euthanasia (Ketamine overdose-350 mg/kg/ip) ${ }^{29}$ of animals or if found dead. Macroscopic examination of organs and tissues and Histo-pathological examinations are to be done only if changes are found on gross or macroscopic examination of their organs and tissues of these animals or if the highest dose group reveal significant changes. Euthanasia: Immediately for Moribund animals and for others at the end of the study (90 days) Ketamine over dose (350 mg/kg/ip).

\section{Ethical approval}

The experimental protocol was approved by the Institutional Animal Ethical Committee (IAEC), Yenepoya University and care of laboratory animals was taken as per Committee 
for the Purpose of Control and Supervision of Experiments on Animals (CPCSEA) guidelines.

\section{RESULTS}

\section{Acute toxicity test}

At the single oral limit dose of $2000 \mathrm{mg} / \mathrm{kg}$, in a group of six mice, no signs of abnormality, morbidity or mortality were observed during 14 days of observation.

\section{Chronic toxicity study}

Significant differences between the treated and control groups were observed in the following parameters: Loss of Auditory startle (alarm reaction), Aggressiveness (Control $>$ treated), Nasal discharge, Dyspnoea (Figure 2: Chronic toxicity - Physical examination and behavioural observations). There were 6 deaths during the study, but there was no significant difference in mortality rate between groups. At necropsy, tracheitis was observed in 3 cases. Histo-pathological analysis of liver and kidney samples did not show any sign of toxicity in any of the tested animals.

Results from Photoactometer test indicates dose dependent increase in sedative property without motor incoordination as indicated by all animals passing rota rod test (Figure 3).

VwRHEE was not found to be toxic at the dose ranges during the period of 90 days as per physical examination, behavioural observation, biochemical, haematological (Table 1), gross necropsy and Histo-pathological reports. The drugs were administered daily for 90 days, the animals were observed daily for any untoward effect, few animals showed loss of auditory startle (alarm reaction), aggressiveness, and nasal discharge. It was also observed that aggressiveness of some animals in the control group. Dyspnoea were also observed in the last two weeks.

\section{DISCUSSION}

'Valerian' the herbal formulation of Valeriana wallichii rhizome is one of the most widely used herb all over

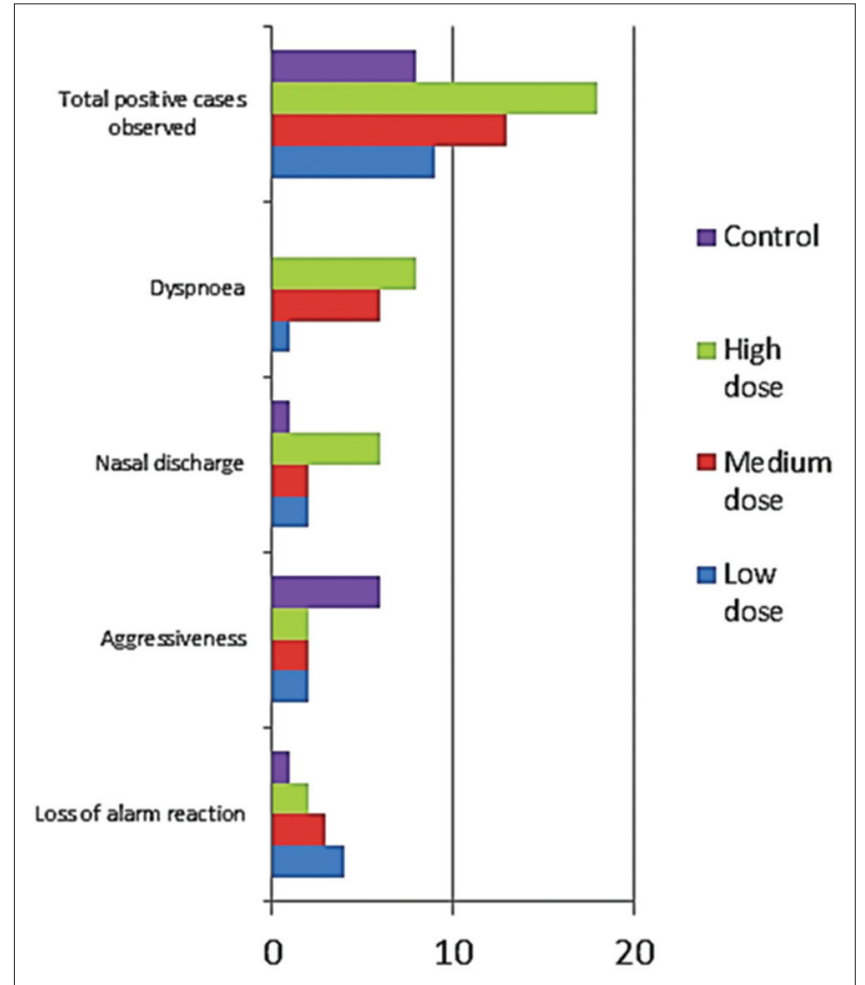

Figure 2: Chronic toxicity - Physical examination and behavioural observations

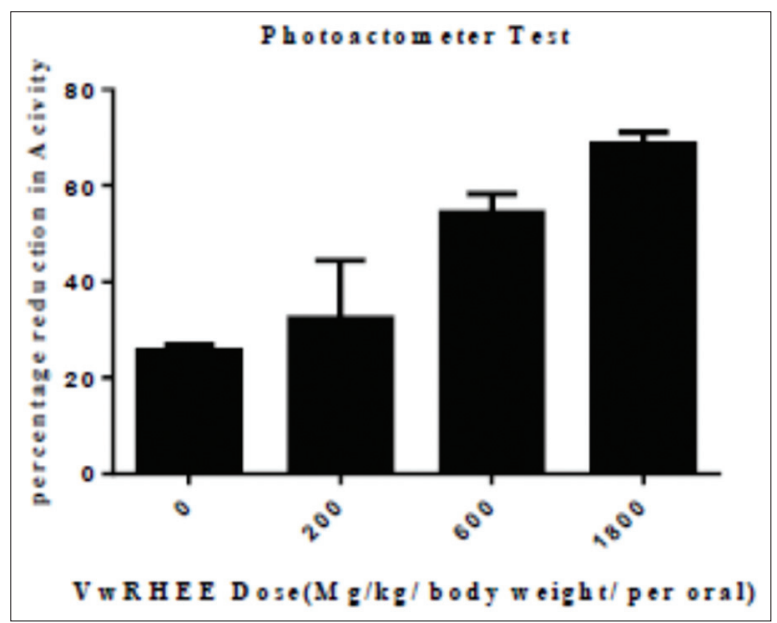

Figure 3: Photoactometer test

\section{Table 1: Chronic toxicity - Haematology and Biochemistry}

\begin{tabular}{lcccc}
\hline Parameter & Control & \multicolumn{3}{c}{ VwRHEE } \\
\cline { 3 - 5 } & & $\mathbf{2 0 0} \mathbf{~ m g / k g}$ & $\mathbf{6 0 0} \mathbf{~ m g / k g}$ & $\mathbf{1 8 0 0} \mathbf{~ m g / k g}$ \\
\hline WBC/cu mm & $5273.33 \pm 41.1$ & $5290 \pm 58.88$ & $5253.33 \pm 33.99$ & $5293.33 \pm 20.55$ \\
RBC (million/cu mm) & $3.83 \pm 0.13$ & $3.87 \pm 0.09$ & $3.9 \pm 0.082$ & $3.9 \pm 0.16$ \\
Lymphocytes (\%) & $41.67 \pm 1.7$ & $39.67 \pm 1.7$ & $40 \pm 2.16$ & $40 \pm 2.21$ \\
Platelet count (lakhs per cu mm) & $1.87 \pm 0.05$ & $1.8 \pm 0.08$ & $1.89 \pm 0.05$ & $1.84 \pm 0.05$ \\
Neutrophil (\%) & $54.67 \pm 1.25$ & $54.33 \pm 0.47$ & $53.33 \pm 0.47$ & $53.67 \pm 1.25$ \\
Hb (g/dl) & $12.5 \pm 0.08$ & $12.63 \pm 0.13$ & $12.5 \pm 0.12$ & $12.7 \pm 0.05$ \\
Blood sugar (mg/dl) & $128.33 \pm 1.25$ & $130.33 \pm 3.3$ & $131 \pm 2.94$ & $129 \pm 2.45$ \\
SGPT (IU/ml) & $24 \pm 0.82$ & $23.33 \pm 0.47$ & $23.7 \pm 0.47$ & $24 \pm 1.41$ \\
SGOT (IU/ml) & $20.33 \pm 0.94$ & $20 \pm 0.82$ & $19.33 \pm 0.47$ & $20.67 \pm 0.47$ \\
\hline
\end{tabular}


the world for insomnia, stress etc as a neutraceutical or herbal medicine. American and Europian Pharmacopoeias have published special editions of Valerian. Indian Vedic literature, mainly ayurvedic scripts have mentioned many herbal preparations and are being used, but most of them are not scientifically validated. Many organizations like WHO and ICMR have expressed the urgent need for validation of indigenous medicines as these could be potential alternative to fill in the treatment gap due to lack of sufficient supply and further which may help in the discovery of novel active principles and targets. The pharmacological validation of herbal formulation has to be preceded by preclinical toxicity studies and this study is meant to partly fill that gap. There are several compounds isolated from this herb in the pipeline of drug development like Valerianic acid. These kinds of studies are significant from both health care and economic development of the country. Reports from several preclinical studies and empirical human use suggests pleiotropic effects of the herb, this could be scientifically evaluated with clinical trials if the detailed preclinical toxicity studies are available.

The present study is a preliminary step towards pharmacological and toxicological profiling of the herb to aid the rational clinical application. Acute toxicity and 90 day chronic toxicity study is essential but not enough to meet the requirements prior to commencement of human trial. Considering the long term use of the herb in humans a chronic toxicity study of one year duration is the minimum requirement as per WHO guidelines on evaluation of safety of herbal medicines. Further conventional guidelines also suggest toxicity study in multiple species in order to improve predictive power of the effects in humans. Most of the adverse effects observed in the study were mild and the sedative property in compliance with reports on CNS depressant and GABAergic activities of the extract. Valerianawallcibii rhizome hydro-ethanolic extract is found to be safe with mild adverse effects in few animals; most of whichwasnot dose dependant indicating that the effects may be related to other variables like artefacts or to handling.

From this work it could be concluded that Valerianawallcibii rhizome hydroethanolic extract didn't exhibit mortality, morbidity or any other neurologic, heamatologic, biochemical adverse effectsapart from sedation which is extension of their known pharmacological activity, at $200 \mathrm{mg} / \mathrm{kg}, 600 \mathrm{mg} / \mathrm{kg}$ and $1800 \mathrm{mg} / \mathrm{kg}$ oral treatment for 90 days in healthy adult Swiss albino mice.

\section{CONCLUSION}

From this work it could be concluded that Valerianawallibiii rhizome hydroethanolic extract didn’t exhibit mortality, morbidity or any other neurologic, hematologic or biochemical adverse effects apart from sedation which is extension of their known pharmacological activity, after single oral dose of $2000 \mathrm{mg} / \mathrm{kg} \mathrm{bw}$ (14 days of observation) or after once daily $200 \mathrm{mg} / \mathrm{kg}, 600 \mathrm{mg} / \mathrm{kg} 1800 \mathrm{mg} / \mathrm{kg}$ oral treatment for 90 days in healthy adult Swiss albino mice.

\section{ACKNOWLEDGEMENTS}

We would like to thank Mr. Sudhakar Shetty and Mr. Suresh Kumar. S Bioanalytical Service Department, Sequent Research Ltd, Mangalore, Dr. Vinitha.R.Pai, Professor, Department of Biochemistry, Deputy Director Research Yenepoya University, Dr. Ravi Rao, Professor, Alvas Ayurvedic Medical College, Moodbidri, and Dr. Navneet Sharma, Sr. Lecturer, Rajiv Gandhi Government Ayurvedic College, Paprola, Himachal Pradesh, Mr. S. Purushottam Nayak, Deepak memorial computerized laboratory and Dr. Kalyan Chakravarthi Kosuri.

\section{REFERENCES}

1. Houghton PJ. The scientific basis for the reputed activity of Valerian. Journal of Pharmacy and Pharmacology 1999; 51(5): 505-512.

2. World Health Organization (1993). Research guidelines for evaluating the safety and efficacy of herbal medicines.

3. Singhal HK, Neetu and Lovelyn J. A comprehensive review on Tagara (Valeriana wallichii). Ayurpharm Int J Ayur Alli Sci 2013;2(5):144-150.

4. Houghton PJ. The Scientific Basis for the Reputed Activity of Valerian. Journal of Pharmacy and Pharmacology 1999; 51: 505-512.

5. Sahu S, Ray K, Yogendra Kumar MS, Gupta S, Kauser H, Kumar $S$, et al. Valeriana wallichii root extract improves sleep quality and modulates brain monoamine level in rats. Phytomedicine 2012; 19(10): 924-929.

6. Lovelyn J, Rejeesh EP and Rao SN. Supraadditive Effect Of Hydroethanolic Extract of Valeriana wallichii (Indian Valerian) Root And Phenobarbitone Against Maximal Electroshock Seizure In Mice. International Journal of Bioassays 2013; 2.08: 1158-1161.

7. Lovelyn J and Rao SN. Anticonvulsant Activity Of Hyrdroethanolic Extract of Valeriana wallichii Root On Maximal Electroshock Induced Seizure Model In Swiss Albino Mice. International Journal of Universal Pharmacy and Bio Sciences 2013; 2(3).

8. Pilkhwal SS, Mathela CS and Chopra K. Antidepressant effect of Valeriana wallichii patchouli alcohol chemotype in mice: behavioural and biochemical evidence. Journal of Ethnopharmacology 2011; 135(1): 197-200.

9. Pilkhwal SS, Mathela CS and Chopra K. Involvement of nitric oxide (NO) signalling pathway in the antidepressant activity of essential oil of Valeriana wallichii Patchouli alcohol chemotype. Phytomedicine 2011; 18(14): 1269-1275.

10. Fazal S, Karim $\mathrm{N}$ and Ibrar M. Anti-inflammatory activity of methanolic and aqueous extracts of Valeriana wallichii DC rhizome. Pak J Plant Sci 2007; 13: 103-108.

11. Kim J, Seo SM, Lee SG, Shin SC and Park IK. Nematicidal 
activity of plant essential oils and components from coriander (Coriandrumsativum), oriental sweetgum (Liquidambar orientalis), and valerian (Valeriana wallichii) essential oils against pine wood nematode (Bursaphelenchusxylophilus). Journal of Agricultural and Food Chemistry 2008; 56(16): 7316-7320.

12. Ghosh S, Debnath S, Hazra S, Hartung A, Thomale K and Schultheis $\mathrm{M}$, et al. "Valeriana wallichii root extracts and fractions with activity against Leishmania spp." Parasitology research 2011; 108(4): 861-871.

13. Gilani $A H$, Khan $A U$ and Subhan F. Ethnopharmacological basis for the use of Valeriana wallichii in hypermotility disorders of the gut. Iranian Journal of Pharmaceutical Research 2010: 54-54.

14. Khan A and Gilani AH. Antidiarrhoeal and bronchodilatory potential of Valeriana wallichii. Natural Product Research 2012; 26(11): 1045-1049.

15. Shrivastava SC and Sisodia CS. Analgesic studies on Vitexnegundo and Valeriana wallichii. Indian Veterinary Journal 1970; 47: 170-175.

16. Syed SN, Rizvi W, Kumar A, Khan AA, Moin S and Ahsan A. Antioxidant and hepatoprotective activity of ethanol extract of Valeriana wallichii in CCL4 treated rats. British Journal of Pharmaceutical Research 2014; 8: 1004.

17. Sadras SR, Sridharan $S$ and Jeepipalli SPK. In vitro Neuroprotective Effect of Valeriana wallichii Extract Against Neurotoxin and Endoplasmic Reticulum Stress Induced Cell Death in Sh-Sy5y Cells. Advanced Journal of Phytomedicine and Clinical Therapeutics 2014; 2(4): 509-523.

18. Cristina $\mathrm{W}$, Marder M, Viola $\mathrm{H}$, Medina JH and Paladini AC. Isolation and identification of 6-methylapigenin, a competitive ligand for the brain GABA (A) receptors, from Valeriana wallichii." Planta Medica 2002;68(10): 934-936.

19. Gilani $A H$, Khan $A U$, Jabeen $Q$, Subhan $F$ and Ghafar $R$. Antispasmodic and blood pressure lowering effects of Valeriana wallichii are mediated through $\mathrm{K}+$ channel activation. Journal of
Ethnopharmacology 2005; 100(3): 347-352.

20. Pilkhwal SS, Chandra MS and Kanwaljit C. Elucidation of possible mechanism of analgesic action of Valeriana wallichii DC chemotype (patchouli alcohol) in experimental animal models. Indian Journal of Experimental Biology 2010; 48(3): 289-293.

21. Chari VM, Jordan M, Wagner $H$ and Thies PW. A 13 C-NMR study of the structure of an acyl-linarin from Valeriana wallichii. Phytochemistry 1977; 16(7): 1110-1112.

22. Wang R, Xiao D, Bian YH, Zhang XY, Li BJand Ding LS, et al. Minoriridoids from the roots of Valeriana wallichii. Journal of Natural Products 2008; 71(7): 1254-1257.

23. Pande $A$ and Shukla $Y N$. Naphthoic acid derivative from Valeriana wallichii. Phytochemistry 1993; 32(5): 1350-1351.

24. Pande A, Uniyal GC and Shukla YN. Determination of chemical constituents of Valeriana wallichii by reverse phase HPLC plus. Indian Journal of Pharmaceutical Sciences 1994; 56(2):56.

25. Glaser J, Martina S, Heidrun M, Hazra B and Holzgrabe U. Antileishmanial and Cytotoxic Compounds from Valeriana wallichii and Identification of a Novel Nepetolactone Derivative. Molecules 2015; 20(4): 5740-5753.

26. Bhattacharyya D, Jana U, Debnath PK and Sur TK. Initial exploratory observational pharmacology of Valeriana wallichii on stress management: a clinical report. (2007).

27. Tiwari P, Kumar B, Kaur M, Kaur G and Kaur H. Phytochemical screening and extraction: a review. International epharmaceutica sciencia 2011; 1: 98-106.

28. Tupper DE and Wallace RB. Utility of the neurological examination in rats. Acta Neurobiol Exp (Wars) 1980; 40(6): 999-1003.

29. Rajesh H, Rejeesh EP and Rao SN."Ketamine as a single general anesthetic agent for oral surgical procedures in Wistar albino rats-An experimental study. International Journal of Bioassays 2013; 2(08): 1094-1097.

\section{Authors Contribution:}

LJ - Concept and design of the study, reviewed the literature, conducted experiment, collected and analysed data, manuscript preparation and critical revision of the manuscript; RE - Concept and design of the study, reviewed the literature, manuscript preparation and critical revision of the manuscript; SNR - Concept and design of the study and critical revision of the manuscript.

Reprint Request:

Dr. Rejeesh.E.P, Assistant Professor, Department of Pharmacology, Government Medical college, Palakkad, Kerala, India, 678013, Contact Number 07025653599, email - HYPERLINK "mailto:rejeesh83@gmail.com" rejeesh83@gmail.com.

Source of Support: Ethnopharmacology Lab- Department of Pharmacology, Yenepoya Medical College, Mangalore, Karnataka, India. 575018. Conflict of Interest: None. 